\title{
Los Congresos en América Latina: legislaturas reactivas, potencialmente activas
}

\author{
Mariana Llanos y Detlef Nolte
}

\section{Resumen}

Este artículo analiza el papel de los parlamentos latinoamericanos en los procesos de elaboración e implementación de políticas públicas durante el presente período democrático. Se toma como punto de partida la caracterización de los parlamentos de la región como legislaturas reactivas. Dicha caracterización reconoce, por un lado, que la iniciativa legislativa recae en general en el Presidente y, por otro, que las reacciones de los parlamentos no sólo pueden variar sino que el espectro de tal variación es bastante amplio. A continuación, se destaca aquí la multifuncionalidad de los parlamentos, esto es, su participación tanto en la elaboración de las leyes como en el desempeño de funciones de control político, lo cual no ha sido suficientemente resaltado en la literatura sobre el tema.

Palabras Clave: parlamentos - América Latina - legislaturas reactivas - políticas públicas - democratización.

\begin{abstract}
This article analyzes the role of Latin American parliaments in the processes of formulation and implementation of public policies during the current period of democratization. The starting point of this analysis is the already established characterization of these parliaments as reactive legislatures, which not only acknowledges that the legislative initiative belongs to the president, but also that parliamentary reactions are wide and varied. Then, the article emphasizes the multifunctional role of parliaments, that is, the fact that they participate in the production of laws as well as in activities of political control, the latter often disregarded in current characterizations.
\end{abstract}

\section{Introducción}

Por muchos años, los parlamentos latinoamericanos no despertaron mayor interés en la ciencia política. Aunque algunos trabajos fueron publicados durante los años '60 y a comienzos de los '70 (por ejemplo Agor, 1971), la predominancia de regímenes autoritarios en la mayoría de los países no constituía el marco más propicio para el desarrollo de estudios sobre el tema. Sin embargo, con la tercera ola de democratización iniciada a fines de los años '70 -y la consecuente celebración regular de elecciones y reapertura de parlamentos a lo largo del continente- el estudio de las instituciones democráticas y su funcionamiento comenzó a adquirir 
cada vez más relevancia. Por otra parte, este cambio fundamental en el contexto político se sumó al auge simultáneo del "nuevo institucionalismo" en las ciencias sociales (March y Olsen, 1989; Peters, 1999), con lo cual el número de trabajos sobre el tema sólo ha ido en aumento desde entonces.

Desde mediados de los años '90, un área de investigación dedicada a los parlamentos se ha ido conformando en los estudios comparativos sobre los sistemas políticos de América Latina. Varios de los trabajos producidos hasta la fecha han adquirido relevancia, como las encuestas de élites parlamentarias de la Universidad de Salamanca, las publicaciones coordinadas por Scott Morgenstern y Benito Nacif (2002) o los tomos de la Universidad de Salamanca sobre el poder legislativo en América Latina (Alcántara et al., 2005a; 2005b). Para los países individualmente contamos con interesantes estudios empíricos sobre el papel de los parlamentos en los sistemas políticos correspondientes ${ }^{1}$. En los trabajos más actuales sobre la implementación de políticas públicas en América Latina, los parlamentos figuran como un actor de relevancia (IADB, 2005: 41-56).

A pesar de estos importantes avances, el estudio de las legislaturas del continente se encuentra todavía en una fase embrionaria. Así, se ha afirmado recientemente que "el estudio de los parlamentos latinoamericanos ha sido objeto de un olvido histórico motivado en gran parte, por los efectos de la atención académica de la denominada preponderancia presidencialista y por el escaso desarrollo de la poliarquía en la región" (Alcántara, García y Sánchez, 2005b: 283). Del mismo modo, con la proliferación de estudios sobre Presidentes y Congresos, tenemos un mayor conocimiento sobre el tema pero todavía bastante desigual entre los casos, por lo que, como se ha afirmado también, "the comparative knowledge of how legislative institutions operate is still quite limited". De esta manera, "a detailed and empirically precise classification of Latin American legislatures in terms of their policymaking role is not possible at this time" (IADB, 2005: 53).

No obstante, cuando nuestros países se acercan a los veinticinco años de vida democrática, es casi inevitable preguntarse qué rol ha cabido a esta institución representativa a lo largo de estos años. Sin perder de vista las limitaciones señaladas en el párrafo anterior, este artículo analiza, específicamente, el papel de los parlamentos latinoamericanos en los procesos de elaboración e implementación de políticas públicas ${ }^{2}$. Es sabido que el contexto que enmarcó el trabajo parlamentario durante las últimas casi tres décadas se caracterizó, en la mayoría de

1 Por ejemplo, sobre el Congresos argentino, ver Llanos (2002); Mustapic (2002), el Congreso chileno, ver Huneeus/Berríos (2004); Huneeus (2005); Siavelis (2000), o el Congreso de Brasil, ver Figueiredo/Limongi (1989; 2000).

2 Por cierto, los parlamentos cumplen también la importante función de la representación política, que no trataremos aquí sino indirectamente, pero sobre la que la ciencia política ha avanzado también de manera considerable. Sobre este tema se destacan, a modo de ejemplo, los trabajos sobre el votante y el parlamentario medio de Colomer y Negretto (2005), el proyecto sobre élites parlamentarias de la Universidad de Salamanca que recolecta opiniones y actitudes de miembros de la Cámara baja (http:// iberoame.usal.es/proyectos.htm) y los trabajos sobre carreras políticas de la conferencia "Political Recruitment and Democracy in Latinamerica" (http://www.wfu.edu/politics/conference/paper.htm). 
los casos, por los avances unilaterales del poder ejecutivo y el incremento de las atribuciones constitucionales de este poder para intervenir en el proceso legislativo. A pesar de ello, resulta difícil sostener uniformemente -ni para todos los casos ni para el mismo país a lo largo de los años- que el parlamento ha sido, en consecuencia, impotente o inoperante frente al predominio del Ejecutivo. De hecho, se suele advertir que en países con presidencias fuertes, como Argentina y Chile, la participación del Congreso en la producción de políticas públicas puede diferir considerablemente: mientras en Argentina es a menudo caracterizada como deficiente, en Chile lo es como constructiva ${ }^{3}$. Hoy en día sabemos mucho más sobre los parlamentos en América Latina que hace una década atrás pero todavía quedan preguntas abiertas: ¿cuáles son los rasgos variables que definen un parlamento fuerte en los sistemas presidenciales latinoamericanos? ¿Cómo medir el poder y la influencia de los Congresos? En este artículo se discuten algunas respuestas a estas preguntas.

Nuestro trabajo toma como punto de partida la caracterización de los parlamentos de la región como legislaturas reactivas (Morgenstern, 2002: 441-43; Cox y Morgenstern, 2002: 448-50). Entendemos que la misma se ajusta a la realidad latinoamericana al reconocer, por un lado, que la iniciativa legislativa recae en general en el Presidente y, por otro, que las reacciones de los parlamentos no sólo pueden variar sino que el espectro de tal variación es bastante amplio. La siguiente sección de este artículo introduce el debate académico sobre el papel de los parlamentos en la región y explica cómo se llega a la caracterización de legislaturas reactivas. A continuación, la sección tres señala que una limitación de esta caracterización es que se centra solamente en una de las funciones del parlamento -la producción de leyes-, mientras que las legislaturas participan de distintas maneras en la formulación de políticas. Enfatizamos, entonces, que tan centrales como las tareas de "control legislativo" son las tareas de "control político" del parlamento (Sartori, 1992), para cuyo desempeño los parlamentos de la región también se encuentran equipados en diferente medida. Entendemos que cualquier apreciación sobre el poder parlamentario debería tener presente esta multifuncionalidad. Por ello, la tercera sección muestra cómo la misma se entrecruza con el carácter "reactivo" del parlamento en la producción de las leyes.

Por cierto, también nos interesa comprender por qué algunas legislaturas son y han sido capaces de reaccionar de forma más participativa o constructiva que otras. Así, la cuarta sección se ocupa de los factores que influyen en el comportamiento legislativo. Nuestra intención aquí es mostrar que, frente al peso indiscutible de factores contextuales -disposiciones constitucionales, dinámica del sistema de partidos, incentivos electorales-, el análisis de otro tipo de factores, que podrían calificarse como "endógenos" u organizativos, ha ido cobrando relevancia (Alcántara et al., 2005b; Santiso, 2005; Saiegh, 2005; IADB, 2005). Se trata del aspecto más novedoso de la investigación sobre parlamentos de la 
región, cuyo impacto todavía no es uniformemente evaluado, por lo cual nos interesa analizar este tipo de factores y mostrar su potencial influencia, como también las limitaciones de los estudios realizados hasta la fecha. Finalmente, nuestro trabajo concluye con una discusión sobre el alcance de la clasificación de legislaturas reactivas. Recurrimos, en este punto, a la literatura sobre las crisis políticas que tuvieron lugar en la región a lo largo de estas casi tres décadas para destacar, en consecuencia, qué legislaturas reactivas en tiempos normales pueden, no obstante, desempeñarse activamente en épocas de crisis.

\section{"Sellos de goma" vs. legislaturas reactivas}

Con el peso del pasado autoritario y la tradición caudillista y concentradora de poder prevaleciente en muchos países del continente, las perspectivas para la consolidación del parlamento como ámbito central de deliberación y adopción de políticas no eran, de entrada, demasiado alentadoras para las democracias de la tercera ola. Tampoco la puesta en práctica de algunas constituciones "hiperpresidencialistas" ofrecía, según algunos autores, incentivos institucionales para que ello sucediera ${ }^{4}$. Por cierto, desde principios de siglo, se observaba en la región una tendencia creciente a fortalecer los poderes legislativos del Presidente (Negretto, 2006). Dicha tendencia sólo fue reforzada por los cambios constitucionales que tuvieron lugar a partir de 1978, siendo el ejemplo más claro de ello el número creciente -aunque todavía minoritario- de constituciones que otorgaron a los Presidentes la capacidad de emitir decretos de contenido legislativo (Brasil, 1988; Colombia, 1991; Perú, 1993; Argentina, 1994).

A los legados históricos se sumaba, además, el contexto de crisis económica en que las instituciones democráticas comenzaron a funcionar. En efecto, profundos shocks externos golpearon a los países de la región en los años '80, los cuales fueron sucedidos por la implementación de ambiciosos programas de reformas neoliberales. Estos programas apuntaron, básicamente, a la reducción del papel del Estado en la economía y a la expansión de las fuerzas del mercado. La implementación de las políticas públicas diseñadas para paliar la crisis y cambiar el modelo estado-céntrico alentó, por su parte, las visiones más pesimistas sobre la consolidación del régimen político: la imposición de políticas públicas desde arriba y la concentración de poder político en la institución presidencial que se observaba a lo largo del continente a principios de los años '90 (Przeworski, 1995), contradecía las expectativas sobre un estilo democrático de adopción de políticas,

$4 \quad$ El término hiperpresidencialista fue acuñado por Carlos Nino (1992) al referirse a las facultades que la constitución argentina de 1853 otorgaba a los Presidentes (la posibilidad de nombrar sin restricciones a los miembros del gabinete y personal de la administración pública; las competencias para dictar el estado de excepción y para intervenir las provincias, etc.). Vistos desde hoy, los poderes del Presidente eran bastante limitados en la constitución de 1853, situación que cambiaría notablemente con la reforma de 1994 . 
esto es, la posibilidad de la participación ampliada de actores sociales y políticos, y la deliberación y adopción de políticas en la arena parlamentaria. El mutuo condicionamiento de las reformas neoliberales y la concentración de poder en los Presidentes fueron incluso vistos como inevitables por algunos autores (Philip, $1993 ; 1998 ; 1999)^{5}$. A raíz de ello, las democracias latinoamericanas pasaron a ser calificadas como "democracias delegativas" (O'Donnell, 1994), democracias de baja intensidad, democracias vacías, o democracias by default (Diamond, 1996) ${ }^{6}$.

Estos análisis llamaban la atención sobre el abuso de recursos de excepción para llevar a cabo las reformas económicas, particularmente, la tendencia a adoptar decisiones de tipo legislativo de manera unilateral. Según estos estudios, el poder ejecutivo logró implementar sus políticas a través de la usurpación de potestades legislativas a los parlamentos, por lo que el proceso político se redujo a elecciones, decretos y estallidos esporádicos de protesta (Przeworski, 1991). No obstante, a mediados de la década del '90, un buen número de trabajos comenzó a revisar esta interpretación. Por un lado, algunos estudios sobre decretos presidenciales sugirieron que, tales recursos de excepción, en lugar de expresar una usurpación de poder por parte de los Presidentes, en muchos casos mostraban la tolerancia o, aun, la preferencia de las mayorías parlamentarias por esas medidas, al tiempo que invitaban a analizar por qué esto podía suceder (Carey y Shugart, 1998: 2) ${ }^{7}$. Del mismo modo, autores como Figueiredo y Limongi (1999; 2000; Limongi \& Figueiredo, 1998; 2004), comenzaron a describirlos como "poderes de agenda", esto es, como medios para determinar cuáles son las propuestas consideradas por el Congreso y cuándo lo son. Un mayor poder de agenda implica, según los autores, la capacidad del Ejecutivo de influir de manera directa en el trabajo legislativo y de mitigar los efectos de la separación de poderes, al mismo tiempo que induce a los parlamentarios a cooperar. De este modo, poderes de agenda presidenciales -tales como los mencionados decretos, la iniciativa legislativa del Presidente en determinadas áreas (como el presupuesto), o la posibilidad de establecer prioridades en la agenda legislativa a través de "urgencias"- comenzaron a ser interpretados como instrumentos para lograr una mejor cooperación interins-

5 "In Latin America in the 1990s at any rate the evidence suggests that one can have either a technocratic, reforming state or a genuinely effective system of democratic accountability but that it is very difficult to have both", Philip (1999), p. 237.

6 El concepto más elaborado fue, no obstante, el de "democracias delegativas" de Guillermo O'Donnell, que suscitó un importante debate en el continente. El papel del parlamento en las nuevas democracias no fue ajeno a dicho debate. Según el autor, un rasgo básico de las democracias delegativas es la falta de controles a la autoridad presidencial: "Típicamente, en las DDs (democracias delegativas) (...) otras instituciones, por ejemplo, las cortes y las legislaturas, son molestias que vienen sujetas a las ventajas internas e internacionales de ser un Presidente democráticamente electo. (...) La DD le da al Presidente la ventaja evidente de no tener prácticamente accountability horizontal. La DD tiene la evidente ventaja adicional de permitir la elaboración rápida de políticas, aunque a costa de una alta probabilidad de gruesos errores, de una implementación arriesgada, y de una concentración de la responsabilidad por los resultados en el Presidente", en O’Donnell (1994), pp. 59-62.

Sobre el poder de decreto presidencial, consultar también Krumwiede y Nolte (2000), Amorim Neto y Tafner (2002), Reich (2002), Amorin Neto et al. (2003), Negretto (2004). 
titucional (Colomer y Negretto, 2003) y una "fusión" o convergencia de poderes en los sistemas presidenciales (Nolte, 2005) ${ }^{8}$. En otras palabras, los "poderes de agenda" se estructuran sobre la base de las instituciones que promueven la separación de poderes e intereses (Shugart y Haggard, 2001) y su uso requiere, al menos, de la tolerancia parlamentaria (Limongi y Figueiredo, 2004: 53) ${ }^{10}$. Desde una perspectiva más general, estos poderes acercan a los Presidentes latinoamericanos a la figura de los jefes de gobierno en los sistemas parlamentarios y, a su vez, diferencian al presidencialismo latinoamericano del sistema presidencial norteamericano ${ }^{11}$.

Por otra parte, en algunos países, la idea de que el poder ejecutivo gobierne por decreto sin restricciones fue desafiada también a través de estudios de caso sobre diversos procesos de las reformas económicas (privatizaciones, reforma laboral, apertura de mercados, etc.). Estos estudios mostraron la influencia considerable que el Congreso ejercía en la toma de tales decisiones políticas. Tanto en el caso de Argentina (Alonso, 1998; Eaton, 2001; Etchemendy y Palermo, 1998; Jones, 2001; Llanos, 1998; Mustapic, 2000) como de Brasil (Ames, 1998; Castro Santos, 1997; Lemos, 2001; Palermo, 2000), donde se dieron importantes procesos de reforma estructural, diversos estudios presentaron casos concretos de conflictos y negociaciones ocurridos entre el Presidente y el Congreso. Tales estudios mostraron que el estilo unilateral del Ejecutivo fue, en no pocas ocasiones, frustrado por la nada despreciable capacidad política del Congreso para reaccionar forzando negociaciones y modificaciones a las políticas, e incluso obstruyéndolas.

$8 \quad$ En el caso de Chile, por ejemplo, el poder de agenda del Presidente es bastante amplio, aunque puede afirmarse que esto no es un signo de omnipotencia presidencial. En efecto, la Constitución le otorga al Presidente el derecho de intervenir en cualquier fase del proceso legislativo a través de la deliberación urgente (simple urgencia, suma urgencia y discusión inmediata), pero el Presidente siempre necesita un voto positivo del parlamento para convertir su propuesta en ley y, además, no cuenta con instrumentos de sanción si el parlamento no cumple con los límites de tiempo. En consecuencia, la urgencia es un instrumento para señalar prioridades y organizar el trabajo parlamentario y, en este sentido, sí parece funcionar ya que la tasa de éxito de las iniciativas presidenciales aumentó de acuerdo al grado de urgencia con la que fueron calificadas las mismas, ver Siavelis (2000), p. 60. En la misma línea de argumentación, ver Huneeus y Berrios (2004), pp. 26-32.

9 Shugart/Haggard (2001) introdujeron el concepto de separation of purpose como complemento del concepto de separation of powers. El concepto alude a la emergencia de diversos tipos de intereses (separation of purpose) derivados, por una parte, de la existencia de sistemas electorales distintos para la elección del Presidente y del parlamento y, por otra, del hecho de que tanto el Presidente como los diputados/senadores responden a electorados diferentes.

10 No se puede descartar que los Presidentes que no cuentan con una mayoría legislativa en el parlamento traten de recurrir a alguno de sus poderes de agenda como, por ejemplo, los decretos legislativos, para sortear esa falta de apoyo. En general, tal comportamiento crea tensiones entre el Presidente y el parlamento -como indican los ejemplos de Perú, con Fujimori; o de Brasil, con Collor de Mello- y pone en peligro al sistema democrático al contradecir la lógica institucional del sistema presidencial. Sin embargo, esto no sucede si la Constitución (o las normas jurídicas que la interpretan) parte del supuesto de que existe un acuerdo tácito del parlamento si es que éste no deroga explícitamente el decreto presidencial, o si prevé la facultad presidencial de vetar la derogación del decreto por parte del parlamento. En tal caso, como ilustra el ejemplo de Argentina, es posible gobernar con decretos aun contra la voluntad de la mayoría parlamentaria. Ver Negretto (2004).

11 Ese tópico fue muy bien elaborado por Cox y Morgenstern (2002), pp. 463-465. 
De este modo, la caracterización de las legislaturas como "sellos de goma" de todo lo que decide el Ejecutivo dejó paso a la idea de "legislaturas reactivas", la cual reconoce que la capacidad de iniciativa política reside en el poder ejecutivo, sin que eso implique que éste puede hacer todo sin tomar en cuenta la opinión de las fuerzas políticas con representación parlamentaria. Por cierto, las legislaturas reactivas pueden variar considerablemente en su comportamiento. Cox y Morgerstern (2002) identifican cuatro subtipos de legislaturas reactivas. En los dos extremos los autores ubican a las legislaturas "subordinadas", es decir, aquéllas que cumplen con todo lo que el poder ejecutivo dicta (y que, por lo tanto, se acercan al tipo tradicionalmente referido como "sellos de goma"), y a las "recalcitrantes", que en el extremo opuesto agrupan a las que sólo se ocupan de bloquear los proyectos del Ejecutivo. En el medio, en cambio, se encuentran dos tipos de legislaturas más aptas para trabajar conjuntamente con el Ejecutivo en la producción de leyes. Por un lado, legislaturas que a menudo aprueban los proyectos del Ejecutivo, pero a través de negociaciones que demandan modificaciones a las políticas propuestas. Estas últimas serían las legislaturas más constructivas para la elaboración de políticas. Por otro, legislaturas menos interesadas por las políticas en sí que, para aprobar los proyectos del Ejecutivo demandan, más bien, beneficios parroquiales-venales orientados a legisladores individuales. Este esquema fue retomado y modificado recientemente en un estudio del Banco Inter-Americano de Desarrollo (IADB, 2005: 53-56). El mismo diferencia entre legislaturas reactivas limitadas, legislaturas reactivas obstruccionistas y legislaturas reactivas constructivas.

Varios factores explican los diferentes comportamientos reactivos de las legislaturas. Morgenstern (2002) menciona sus facultades constitucionales, la conformación de mayorías políticas (si el Presidente tiene mayoría o no, y cuán homogénea es ésta) y la motivación de los legisladores por ser reelectos en sus cargos (lo que depende, a su vez, de los sistemas electorales y partidarios). Las variaciones en estos factores -y en otros, como veremos más adelante- no sólo explicarían los diferentes tipos de legislatura reactiva que se observan en el continente, sino también diferentes comportamientos reactivos dentro de un mismo país. Sin perder de vista los variados comportamientos reactivos y sus múltiples causas, nos interesa concluir esta sección remarcando que hoy en día existe bastante consenso entre los analistas en cuanto al papel reactivo de las legislaturas frente a las iniciativas de política del poder ejecutivo -papel que, por otra parte, no es privativo de las legislaturas de la región, sino también propio de otras legislaturas, como aquéllas en sistemas parlamentarios-. No obstante, es preciso recordar que, tanto en sistemas presidenciales como parlamentarios, las legislaturas cumplen otras funciones además de la producción de leyes. Nos referiremos a este tema en la próxima sección. 


\section{Las funciones del parlamento}

Al referirse a las funciones del parlamento, Sartori (1992: 199-201) formula la distinción entre control legislativo y control politico. Con el primer término, el autor alude a la capacidad que tienen las legislaturas para presentar, modificar, demorar y rechazar iniciativas de ley. El foco está colocado aquí en el papel que desempeña el parlamento en el proceso de toma de decisiones. El segundo término, por su parte, hace referencia al seguimiento que el parlamento realiza de las decisiones adoptadas. La mirada, en este caso, está puesta en la implementación. En un sentido similar se pronunciaba Blondel (1973) al referirse a las atribuciones del parlamento. Según este autor, para la producción legislativa, tarea que involucra tanto al poder ejecutivo como al Legislativo, el parlamento cuenta con poderes de iniciación, esto es, con la posibilidad de introducir legislación de su propia autoría; con poderes de reacción, frente a las iniciativas impulsadas por el gobierno, que consisten en propiciar su aprobación, rechazo, modificación o demora; y, por último, con poderes de prevención, es decir, con la alternativa de desalentar la presentación de proyectos del gobierno que no está dispuesto a aprobar. En cambio, el ejercicio de la función de control y supervisión de la implementación de las políticas por parte del gobierno demanda el uso de otros instrumentos institucionales, diferentes de los mecanismos empleados por los parlamentos en la sanción de las leyes. Se trata de instrumentos formales, normalmente reconocidos por la Constitución, cuyo número y forma de uso varían entre los países, pero que, en todos los casos, apuntan a requerir información del poder ejecutivo (como los pedidos de informes o las interpelaciones), a monitorear o investigar sus actividades (como las comisiones de investigación, pero también las comisiones permanentes), y a involucrar al parlamento en la designación de funcionarios (como la prestación de acuerdo para nombramientos) y en su remoción (como el juicio político o la censura de ministros).

Según el politólogo alemán Steffani (1989: 1328), el control parlamentario se define, en forma general, como la capacidad de revisar y sancionar las actuaciones del gobierno y de la administración pública. Sobre la base de esta definición, Steffani (1989: 1326-1327) diferenció seis dimensiones de control parlamentario que incluyen tanto el control legislativo como el control político (ver Cuadro 1). De estas seis dimensiones del control parlamentario, cinco tienen vigencia tanto en sistemas parlamentarios como en sistemas presidenciales, mientras que solamente la última no existe en sistemas presidencialistas (donde puede tener lugar la destitución de ministros pero no del Presidente excepto, por cierto, en el caso de un juicio político).

A pesar de la importancia de la función de control político, los estudios existentes sobre los parlamentos latinoamericanos suelen concentrarse solamente en la producción de las leyes ${ }^{12}$. No resulta entonces sorprendente que, dado que la

12 Ciertamente, existen excepciones. Por ejemplo, Alcántara et al. (2005b). 
Cuadro 1: Dimensiones del control parlamentario (según Steffani)

- Revisión posterior de las actividades del gobierno y de la administración pública;

- Participación permanente y seguimiento de las actividades del gobierno y de la administración pública;

- Control (en cualquiera de las dos formas anteriores) con la posibilidad de intervenir en los actos de gobierno a través de la sanción de las leyes y el presupuesto;

- Posibilidad de obligar al gobierno a dar cuenta de sus actividades de manera pública a fin de iniciar un debate público y, eventualmente, conseguir la sanción posterior por parte del electorado;

- Posibilidad de obligar al gobierno a dar cuenta de sus actividades y, eventualmente, a revertir sus políticas en el proceso legislativo;

- Posibilidad de obligar al gobierno a dar cuenta de sus actividades y, eventualmente, de destituirlo (o de destituir a algunos de sus miembros).

iniciativa legislativa recae normalmente en el poder ejecutivo, se califique a los parlamentos como reactivos, y que, al mismo tiempo, se observen los poderes legislativos desde una perspectiva de suma cero, esto es, cuanto mayores sean los poderes del Presidente en el proceso legislativo, menores son los del parlamento y viceversa. Sin embargo, este cuadro resulta más complejo si incorporamos el control político. En este caso, la iniciativa de actuar recae necesariamente en el poder legislativo, razón por la cual las legislaturas pueden, eventualmente, ser calificadas como activas o pasivas, pero no como reactivas ${ }^{13}$. El siguiente cuadro muestra que, en todos los países, los principales instrumentos de control tienen jerarquía constitucional. Aun más, en los sistemas bicamerales, tales instrumentos se encuentran además duplicados en las dos cámaras legislativas, salvo la participación en nombramientos de cargos públicos que es una atribución de los Senados ${ }^{14}$.

Lo cierto es que poco conocemos sobre el uso de estos instrumentos en la práctica. La concentración de los estudios académicos en el alcance de los poderes legislativos del Presidente no sólo ha descuidado esta otra función parlamentaria central sino que ha dado lugar a la tesis de la falta de controles. Para muchos, no sólo la función legislativa del parlamento es débil sino que los mecanismos de accountability horizontal (O’Donnell, 1998; 2003) no están siendo utilizados. En otras palabras, la brecha sería grande entre los recursos constitucionales con que están dotados los parlamentos y su falta de uso en la práctica. No obstante, la poca investigación empírica existente sugiere que, aunque el uso de los instrumentos

13 Con excepción de la función parlamentaria de confirmar los nombramientos propuestos por el poder ejecutivo. En este caso, el control que ejerce el Congreso (el Senado, en el caso de legislaturas bicamerales) es siempre reactivo porque su tarea es aprobar o rechazar los nombres propuestos por el Ejecutivo. Al respecto, hay también algunas excepciones, ya que la ley o Constitución también pueden establecer que corresponde al poder legislativo proponer al Ejecutivo determinadas designaciones para que éste seleccione. En este caso, el poder legislativo es el que actúa primero.

14 Sólo en el caso de Chile el control parlamentario es competencia exclusiva de la cámara baja. Al Senado le corresponde solamente prestar su acuerdo para el nombramiento de funcionarios. 
Cuadro 2: Principales instrumentos de control con jerarquía constitucional

\begin{tabular}{|c|c|c|c|c|c|c|}
\hline Legislaturas & $\begin{array}{l}\text { Juicio } \\
\text { Politico }\end{array}$ & $\begin{array}{l}\text { Comisiones de } \\
\text { investigación }\end{array}$ & Interpelación & $\begin{array}{l}\text { Pedidos de } \\
\text { información }\end{array}$ & $\begin{array}{c}\text { Censura } \\
\text { de } \\
\text { ministros }\end{array}$ & $\begin{array}{l}\text { Participación en } \\
\text { Nombramientos }\end{array}$ \\
\hline \multicolumn{7}{|c|}{ Bicamerales } \\
\hline Argentina & Sí & Sí & Sí & Sí & Sí & Sí \\
\hline Bolivia & Sí & Sí & Sí & Sí & Sí & Sí \\
\hline Brasil & Sí & Sí & Sí & Sí & No & Si \\
\hline Chile & Sí & Sí & Sí & Sí & No & Sí \\
\hline Colombia & Sí & Sí & Sí & Sí & Sí & Sí \\
\hline México & Sí & Sí & Sí & No & No & Sí \\
\hline Paraguay & Sí & Sí & Sí & Sí & Sí & Si \\
\hline $\begin{array}{l}\text { República } \\
\text { Dominicana }\end{array}$ & Sí & No & Sí & No & No & Sí \\
\hline Uruguay & Sí & Sí & Sí & Sí & Sí & Sí \\
\hline \multicolumn{7}{|c|}{ Unicamerales } \\
\hline Costa Rica & Sí & Sí & Sí & Sí & Sí & Si \\
\hline Ecuador & Sí & No & No & Sí & Sí & Sí \\
\hline El Salvador & No & Sí & Sí & Sí & Sí & Sí \\
\hline Guatemala & Sí & Sí & Sí & Sí & Sí & Sí \\
\hline Honduras & No & Sí & Sí & No & No & Sí \\
\hline Nicaragua & No & Sí & Sí & Sí & No & Si \\
\hline Panamá & Sí & Sí & Sí & Sí & Sí & Si \\
\hline Perú & Sí & Sí & Sí & Sí & Sí & Sí \\
\hline Venezuela & Sí & Sí & Sí & Sí & Sí & Sí \\
\hline
\end{tabular}

Fuente: El cuadro es de nuestra elaboración en base a las constituciones actuales.

Nota sobre los pedidos de información: Si bien algunas Constituciones no reconocen expresamente el derecho de solicitar informes, en general se establece que los ministros deben rendir cuenta de su actuación al menos una vez al año. También en casi todos los casos se establecen pautas para el control de las cuentas públicas y de la ejecución del presupuesto.

de control todavía es precario e insuficiente, algunos de ellos se encuentran activos $^{15}$. Por otra parte, como en la producción de leyes, el funcionamiento de los controles depende de varios factores. Para Moreno, Crisp y Shugart (2003: 91-93) el factor clave que obstaculiza el control legislativo en un sistema presidencial es el predominio del poder ejecutivo y la ausencia de intereses contrapuestos. Esto

15 Lemos (2005) analiza el uso que el Congreso brasileño realiza de tres instrumentos de control parlamentario: los pedidos de información, las propuestas de fiscalización y control, y las convocatorias de autoridades. La autora observa que entre 1988 y 2004 aumentó el uso de estos instrumentos, lo que por lo menos indica que los controles parlamentarios disponibles se encuentran activos. Palanza (2005) rea- 
sucede en dos circunstancias. En primer lugar, bajo los presidencialismos mayoritarios, es decir, en aquellas configuraciones de poder en donde el Presidente cuenta con mayoría en el Congreso, particularmente, cuando el Presidente es jefe de partido. En segundo lugar, la ausencia de intereses contrapuestos se observa, también, cuando los partidos son muy débiles. En este caso, la falta de partidos fuertes limita la capacidad de coordinar la actividad legislativa, lo que hace a los legisladores vulnerables a las presiones y al patronazgo del Ejecutivo. En síntesis, para estos autores, ya sea por partidos fuertes o débiles, los controles parlamentarios no funcionan en el continente.

No obstante, entendemos que la función del control parlamentario debe ser observada desde una lógica distinta. Específicamente, no corresponde esperar mayores actividades de control por parte del partido (o los partidos) de gobierno, sino de los partidos de la oposición ya que la oposición política es el actor más motivado para ejercerla. Desde esta perspectiva, en cuestión de controles, la lógica es similar a la que rige la producción de leyes: un Presidente con una mayoría propia (homogénea) no encontrará mayores obstáculos legislativos ni políticos. Por lo cual también, como se ha señalado con respecto a la producción de leyes, la falta total de controles no parece ser propia de toda la región, sino de algunas legislaturas. En efecto, si retomamos la clasificación de Cox y Morgenstern (2002) y del IADB (2005), podemos observar que sólo a un tipo de legislaturas reactivas -las subordinadas o limitadas- correspondería la falta total de incentivos para controlar. Mientras estas legislaturas serán probablemente también pasivas, aquéllas que buscan bloquear la actuación del poder ejecutivo (legislaturas reactivas recalcitrantes $\mathrm{u}$ obstruccionistas), pueden tornarse bastante activas procurando interponer simultáneamente otro tipo de obstáculos (los juicios políticos y comisiones de investigación pueden servir a esos fines), dando así un rumbo incierto al proceso político.

Entre estos extremos, la gama de posibilidades es amplia, ya que el ejercicio de las funciones de control legislativo y político puede entrecruzarse de diversas maneras. En efecto, las mayorías políticas coincidentes en ambos poderes del Estado no necesariamente traen aparejados parlamentos reactivos y pasivos. Por un lado, diferentes incentivos electorales (basados en diferentes métodos de elección) pueden crear intereses divergentes -o una separation of purpose, según Shugart y Haggard (2001) - entre el Presidente y los parlamentarios de su propio partido. Por otra parte, algunos casos europeos muestran que el poder ejecutivo comanda la producción de leyes pero que el parlamento se desempeña activamente en el ejercicio de sus atribuciones de control y monitoreo de las actividades del gobierno, que están principalmente en manos de la oposición política. Esto muestra,

\footnotetext{
liza un análisis cuantitativo de los mecanismos de control utilizados con mayor frecuencia en la Argentina durante la década del ' 90 : los pedidos de informes escritos, las interpelaciones, los juicios políticos y las visitas del Jefe de Gabinete de Ministros. Este trabajo muestra que el Congreso argentino utiliza algunos mecanismos de control que no requieren de tantas capacidades informacionales y, como ponen en evidencia los pedidos de informes escritos, incluso tiene lugar un diálogo con el poder ejecutivo, ya que éste responde lo que el Congreso demanda.
} 
asimismo, que el ejercicio de un rol "constructivo" por parte de los parlamentos reactivos no es solamente producto de incentivos políticos. Requiere, además, de los recursos institucionales y las capacidades técnicas apropiadas. En la próxima sección intentaremos explicar más detalladamente qué factores afectan el nivel de desempeño de las legislaturas latinoamericanas.

\section{Instituciones, organización y capacidades técnicas del parlamento}

Un buen número de factores afectan el desempeño parlamentario. A grandes rasgos podemos referirnos a factores institucionales y organizativos, aunque en la práctica pueden identificarse varios niveles de análisis, que se interrelacionan entre sí. Ciertamente, con respecto a las instituciones políticas, es sabido que no sólo las normas constitucionales determinan el comportamiento de los actores políticos. Es importante recordar que estas normas interactúan con otras, muchas de las cuales se desprenden del diseño procedimental, conformando "regímenes institucionales" ${ }^{\prime 16}$. Dentro de un régimen institucional, las instituciones componentes interactúan de diferentes modos, sea reforzándose de manera aditiva, sea superponiéndose o neutralizándose, lo cual dificulta cualquier medición sobre el impacto de instituciones individuales ${ }^{17}$. En esta sección nos referimos a los condicionantes institucionales del desempeño parlamentario intentando dar cuenta de esta interrelación.

\section{CONSTITUCIONES, LEYES Y REGLAMENTOS}

En términos generales, es posible sostener que son las normas constitucionales, las que, al otorgar al poder ejecutivo la iniciativa política, confinan al parlamento a una posición reactiva. Sin embargo, las Constituciones latinoamericanas muestran una gran variedad en cuanto al poder de intervención del Presidente en el

16 "To talk of institutional regimes is to emphasise the fact that political systems are based on interrelated institutional and organisational features that systematically structure the way political actors make decisions", ver Kaiser (1998b), p. 205. El concepto de "regímenes institucionales", introducido por Kaiser (1998), p. 525, es una construcción conceptual que se refiere al conjunto de estructuras institucionales y organizacionales interconectadas entre sí que influyen en el comportamiento de los actores políticos de manera sistemática. Kaiser adopta el término "institutional regimes" de Colomer (1996), p. 2, y desarrolla el concepto análitico correspondiente.

17 El lector atento ya habrá advertido que la cuestión es aún más compleja, ya que, entre las reglas formales, se interponen también reglas "informales". De acuerdo con Helmke y Levitsky (2004), las instituciones informales son "reglas socialmente compartidas, que normalmente no están escritas, que son creadas, comunicadas e implementadas por fuera de los canales oficiales", mientras que las instituciones formales son reglas y procedimientos "creados, comunicados y puestos en práctica a través de canales ampliamente aceptados como oficiales" (tales como las instituciones del Estado -legislaturas, cortes- y sus reglas -constituciones, leyes-). Sin perder de vista la importancia de las instituciones informales, en este texto nos referimos particularmente a las formales. 
proceso legislativo. Según los estudios correspondientes, la influencia del parlamento en el proceso de producción de leyes depende de: a) la fuerza del veto presidencial (si es total o parcial, y cuál es la mayoría que necesita el parlamento para derogarlo); b) la existencia de limitaciones formales o temáticas a la participación del parlamento en la redacción de las leyes (o también, la iniciativa exclusiva del Presidente); c) la participación del parlamento en la determinación de los gastos presupuestarios; d) la posibilidad del Congreso de rechazar el plan de presupuesto del poder ejecutivo; e) la facultad presidencial de legislar por decreto; y e) la facultad presidencial de convocar un referendo o plebiscito.

Shugart y Carey (1991) son los autores del estudio pionero para medir el poder presidencial en el proceso legislativo. A partir de ellos se han propuesto otras mediciones, muchas de las cuales toman este trabajo como punto de partida, pero difieren del mismo en diversos aspectos. En general, las diferencias en las mediciones se basan en cuáles son los factores considerados para medir tales poderes, esto es, si sólo se toman en cuenta los poderes de veto y agenda (excluyendo, por ejemplo, la atribución del Presidente para organizar un plebiscito); si se diferencia entre diversas formas de veto (y cómo se lo hace), y cómo se mide la preponderancia del poder ejecutivo en el proceso presupuestario ${ }^{18}$. El siguiente cuadro presenta el ranking de los poderes presidenciales latinoamericanos según cinco diferentes estudios (Shugart/Haggard, 2001; Krumwiede/ Nolte, 2000; Payne et al., 2002; PNUD, 2004; Negretto 2006) ${ }^{19}$. No incluimos aquí ninguna explicación sobre las variables consideradas por cada autor, sino solamente el puntaje final que estos estudios otorgan a cada país ya que nuestro objetivo es comparar de manera directa los índices que estos trabajos proponen. De este modo, el puntaje final corresponde a la cifra entre paréntesis que puede observarse en cada columna, mientras que la cifra de la izquierda se refiere a la ubicación del país en función de tal puntaje. Es decir, el l corresponde al país con puntaje más alto en la escala de poderes presidenciales (o también, el 1 corresponde a la cifra más alta entre paréntesis), el 2 al inmediatamente inferior, y así sucesivamente. Debe tenerse en cuenta que la mayoría de los estudios mide el poder parlamentario desde la perspectiva del Presidente; sólo el índice de Krumwiede y Nolte procede a la inversa, por lo que los puntajes altos entre paréntesis corresponden, en este caso, a un poder legislativo bajo de los Presidentes.

18 Por regla general, los índices de poder presidencial o parlamentario se construyen sobre la base de la adición de los valores de las diferentes variables. Es debatible si es conveniente medir el impacto de los diferentes poderes presidenciales de manera aditiva, más bien puede pensarse que funcionan de manera interactiva. Por eso es novedoso el enfoque de Negretto (2006), que trata de crear un índice interactivo de los poderes legislativos presidenciales como producto de los poderes de agenda y los poderes de veto.

19 No hemos incluido el estudio de Shugart y Carey (1991) porque se refiere a las Constituciones vigentes a principio de los años '90 y no incluye las reformas siguientes (por ejemplo, en Paraguay después de la caída de Stroessner o en Perú después del autogolpe de Fujimori). Además, los estudios de Payne et al. (2002) y del PNUD (2004) se basan en el esquema (actualizado y levemente modificado) de Shugart y Carey (1991). 
Como puede observarse, existe bastante variación en el puntaje otorgado a cada caso. Sin embargo, si tomamos los Presidentes con más poderes legislativos, Chile, Colombia y Ecuador casi siempre se encuentran entre los cinco primeros lugares en el ranking (marcados con color gris), mientras que Argentina, Brasil y Perú también forman parte del grupo de países con Presidentes fuertes, aunque no en todos los estudios considerados. Las mayores variaciones corresponden a la evaluación de Argentina como también al caso de Uruguay, que solamente en el estudio de Negretto (2006) forma parte del grupo de Presidentes poderosos en el proceso legislativo. Por regla general, puede observarse que los Presidentes de Centroamérica y México tienen menos poderes legislativos que sus pares en Sudamérica; en la región sudamericana, el Presidente boliviano y el Presidente paraguayo son los menos poderosos en el proceso legislativo. En síntesis, estos

Cuadro 3: Ranking de los países latinoamericanos según los poderes legislativos de los Presidentes (entre paréntesis valores según escala de cada autor)

\begin{tabular}{|c|c|c|c|c|c|}
\hline & $\begin{array}{c}\text { Shugart/Haggard } \\
(2001)\end{array}$ & $\begin{array}{c}\text { Payne et al. } \\
(2002)\end{array}$ & PNUD (2004) & $\begin{array}{c}\text { Negretto } \\
(2006) \\
\text { Veto/agenda* }\end{array}$ & $\begin{array}{c}\text { Krumwiede/ } \\
\text { Nolte } \\
(2000) \\
\text { parlamento** }\end{array}$ \\
\hline Año & $2000(?)$ & 2000 & 2002 & 2005 & 1998 \\
\hline Escala & $0-8$ & $0-25$ & $0-1$ & $1-4$ & $0-24$ \\
\hline Argentina & $1(6)$ & $9(7.0)$ & $6(0.44)$ & $4(2.94)$ & $5(12.0)$ \\
\hline Bolivia & $7(2)$ & $14(5.0)$ & $16(0.23)$ & $10(1.91)$ & $8(14.5)$ \\
\hline Brasil & $5(3)$ & $4(11.0)$ & $2(0.62)$ & $6(2.68)$ & $5(12.0)$ \\
\hline Chile & $2(4)$ & $3(12.0)$ & $1(0.66)$ & $5(2.80)$ & $3(10,0)$ \\
\hline Colombia & $2(4)$ & $4(11.0)$ & $3(0.59)$ & $1(3.34)$ & 2 \\
\hline Costa Rica & $12(1)$ & $16(2.5)$ & $16(0.23)$ & $15(1.59)$ & \\
\hline Ecuador & $5(3)$ & $1(14.5)$ & $3(0.59)$ & $2(3.29)$ & $4(11.0)$ \\
\hline El Salvador & $7(2)$ & $11(6.5)$ & $10(0.33)$ & $13(1.74)$ & \\
\hline Guatemala & $7(2)$ & $11(6.5)$ & $12(0.29)$ & $11(1.86)$ & \\
\hline Honduras & $12(1)$ & $16(2.5)$ & $13(0.25)$ & $18(1.49)$ & \\
\hline México & $12(1)$ & $16(2.5)$ & $15(0.24)$ & $15(1.59)$ & $11(19,0)$ \\
\hline Nicaragua & $15(0)$ & $7(8.0)$ & $13(0.25)$ & $17(1.51)$ & \\
\hline Panamá & --- & $6(10.5)$ & $7(0.43)$ & $8(2.06)$ & \\
\hline Paraguay & $15(0)$ & $15(3.0)$ & $18(0.19)$ & $9(2.02)$ & $10(17,0)$ \\
\hline Perú & $2(4)$ & $2(13.0)$ & $5(0.50)$ & $7(2.59)$ & $1(7.5)$ \\
\hline Rep. Dom. & $7(2)$ & $7(8.0)$ & $9(0.37)$ & $14(1.70)$ & \\
\hline Uruguay & $7(2)$ & $11(6.5)$ & $8(0.38)$ & $3(2.98)$ & $9(16.0)$ \\
\hline Venezuela & $15(0)$ & $9(7.0)$ & $11(0.30)$ & $12(1.80)$ & $* * * 7(13.0)$ \\
\hline
\end{tabular}

* Solamente poderes de veto y agenda ** los valores en paréntesis se refieren al poder parlamentario, un valor alto implica un poder legislativo bajo del Presidente ${ }^{* * *}$ Constitución de 1961 
trabajos sobre los poderes presidenciales indican una gran variedad en la potencial capacidad de los parlamentos para intervenir en el proceso legislativo, siendo los últimos casos los más apropiados para que ello suceda. Pero este poder, como hemos visto, no depende solamente de las normas constitucionales.

En contraposición con las diferencias existentes en el poder parlamentario concerniente a la producción de leyes, las Constituciones son más uniformes en cuanto a los poderes que otorgan a los parlamentos para ejercer la función de control político (ver Cuadro 2 en sección anterior). Según las mismas, entonces, deberíamos esperar un rol activo en el cumplimiento de esta función. El comportamiento de los parlamentos de la región es, sin embargo, también variado con respecto a esta función, no sólo por la presencia de mayorías parlamentarias favorables al Presidente, sino, como decíamos más arriba, por la intersección de las disposiciones constitucionales con otras normas. En efecto, para llevar adelante las actividades de control parlamentario es preciso que los instrumentos a disposición del legislador estén diseñados de un modo que permita su uso. Por ejemplo, no es suficiente contar con la atribución constitucional o legal de formar comisiones de investigación ya que, si los reglamentos disponen que, para formar dichas comisiones, se requiere del voto de la mayoría, entonces la oposición, en caso de encontrarse en minoría, no tendrá chances de investigar aunque tenga incentivos y razones para hacerlo. Al respecto, resulta interesante traer a colación el caso alemán. En Alemania, a excepción de la moción de censura donde sí entra en juego la mayoría parlamentaria, todos los otros mecanismos de control son reconocidos como un derecho de la oposición política ya que el respaldo parlamentario requerido para su uso es bajo. En efecto, el Reglamento del Bundestag establece variados mecanismos formales de control que sólo requieren para su uso de la solicitud de una de las bancadas, del cinco por ciento de los diputados, de un cuarto de los diputados, o de los diputados individualmente. En dos trabajos recientes, sobre Argentina (Fuchs y Nolte, 2005) y Brasil (Calcagnotto, 2005), se pudo comprobar que éste no era el caso en los dos parlamentos investigados.

Por cierto, en un sistema presidencial los partidos de oposición tienen más chances de ejercer control que en un sistema parlamentario, porque no necesariamente se encuentran en una situación minoritaria. Estando en mayoría en el parlamento, o en alguna de sus cámaras, la oposición puede hacer uso de los mecanismos de control político, como también intervenir activamente en (e incluso bloquear) el proceso de elaboración de leyes. Esta falta de mayorías parlamentarias es una situación recurrente en los presidencialismos de la región, que viene a colación de la fragmentación en los sistemas de partidos (Chasquetti, 2001: 31959; Cheibub, 2002: 295; Payne et al., 2002: 211). La falta de mayorías es también propia de los presidencialismos en general: según un estudio comparativo de democracias presidenciales (Cheibub, 2002: 287), los Presidentes no contaban con mayoría en el parlamento en más de la mitad de los casos (53 por ciento), siendo este porcentaje mayor en sistemas bicamerales (60 por ciento) que unicamerales (46 por ciento). Este último punto nos muestra que, al momento de evaluar las 
capacidades del parlamento, la estructura del mismo, específicamente la estructura unicameral o bicameral, aparece también como un factor importante.

\section{LA ESTRUCTURA DEL PARLAMENTO}

Es notable que, siendo temas como la parálisis legislativa y el gobierno dividido tan preciados por los estudiosos del presidencialismo, se haya prestado hasta ahora tan poca atención al bicameralismo, y a su incidencia en el trabajo parlamentario ${ }^{20}$. Solamente en el debate político, y ciertamente de manera negativa, la estructura del parlamento ha despertado algún interés, básicamente porque un parlamento dividido en dos cámaras implica gastos superfluos que, se argumenta, podrían ahorrarse bajo una estructura unicameral. No obstante, no debe descartarse que una segunda cámara pueda también significar un incremento de la efectividad y la capacidad técnica legislativa. Después de todo, el número de legisladores es mayor, hay más comisiones parlamentarias, el personal de apoyo técnico crece y, con todo ello, aumenta también la experiencia político-profesional del Congreso.

Son varias las formas en que la estructura parlamentaria puede afectar el cumplimiento de las funciones del parlamento. En primer lugar, la inclusión de una segunda cámara suele ser asociada con cuestiones de representación política, típicamente de los intereses de entidades territoriales en sistemas federales, pero también responde a razones de eficiencia (ver Llanos y Nolte, 2003; Nolte, 2004). Para Tsebelis y Money (1997: 40), el bicameralismo incentiva un mutuo "control de calidad" entre las cámaras y aumenta la información disponible en el trabajo legislativo. Por otra parte, el bicameralismo contribuye al sistema de pesos y contrapesos, al duplicar los controles del poder legislativo sobre los actos del gobierno y al ofrecer contrapesos frente al peligro de una tiranía de la mayoría o una "tiranía de la cámara baja" (The Federalist Papers No.62). Estos rasgos del trabajo parlamentario bajo sistemas bicamerales no necesariamente deben ser interpretados como una ventaja. La presencia de dos cámaras legislativas complejiza el proceso de elaboración de leyes y la formación de mayorías de gobierno, provocando demoras y bloqueos. En síntesis, existen bastantes diferencias en la forma en que operan los sistemas legislativos bicamerales y unicamerales y, dado que en el continente ambos tipos de legislaturas están igualmente representados ${ }^{21}$, es conveniente comenzar a preguntarse sobre su importancia y efectos (ver Nolte, 2006b) ${ }^{22}$.

20 Incluso trabajos recientes (como el ya citado del IADB, 2005), que representan importantes contribuciones al estudio de los parlamentos de la región, omiten esta distinción.

21 Los sistemas bicamerales del continente abarcan México y República Dominicana, más siete países de Sudamérica: Argentina, Bolivia, Brasil, Chile, Colombia, Paraguay y Uruguay.

22 Esta falta de información motivó un proyecto sobre los sistemas bicamerales del continente que desarrollamos en Hamburgo entre 2001 y 2004. Para resultados de este proyecto ver, entre otros, Llanos y Nolte (2003); Llanos y Lemos (2006); Llanos y Sánchez (2006); Nolte (2004); Nolte y Sánchez (2004); Sánchez (2004); Sánchez, Nolte y Llanos (2005). Para otros estudios comparativos sobre los Senados latinoamericanos ver Neiva (2004); Schiavon (2004). 
La inclusión de la dimensión unicameral/bicameral en nuestros análisis puede afectar de diversas maneras nuestra percepción sobre los parlamentos. A modo de ejemplo, se afirma a menudo que las legislaturas de la región carecen de las capacidades técnicas para llevar a cabo sus funciones (IADB, 2005) o, en otras palabras, que el parlamento se encuentra en desventaja con el poder ejecutivo en lo que concierne a la información. Esta asimetría, muchas veces originada en el carácter técnico de las políticas, contribuye a que éstas se transformen en un dominio del Ejecutivo, impidiendo un control efectivo por parte del parlamento. Entre los factores que afectan el déficit técnico de los parlamentos latinoamericanos, se suele citar la corta permanencia de los legisladores en el Congreso. Se sostiene al respecto que la existente escasez de recursos para un trabajo legislativo eficiente no sería tal si los legisladores acumularan muchos años de experiencia en la labor parlamentaria. Pero esto no parece suceder en los parlamentos donde los legisladores no permanecen largo tiempo en sus puestos. Al ser la tasa de reelección del legislador muy baja ${ }^{23}$, el Congreso no llega a convertirse en un ámbito adecuado para la adquisición de capacidades técnicas, las cuales se refieren tanto a la profesionalización política como a la especialización de los parlamentarios. Esto no sólo dificulta las actividades de fiscalización al momento de la implementación de las políticas sino también el control a través de la elaboración de las leyes, ya que los legisladores no tienen los conocimientos necesarios para propiciar una redacción detallada de las leyes. En efecto, un estilo de redacción detallado sería otra forma de reducir las oportunidades de las agencias ejecutivas para actuar de manera discrecional.

Aunque la tesis sobre los efectos de la corta permanencia del legislador en el Congreso es bastante persuasiva, puede afirmarse que la evidencia al respecto es sólo parcial, especialmente si la observamos desde la perspectiva de los "regímenes institucionales", desde la interacción entre normas y estructura, o desde la estructura bicameral/unicameral. Por ejemplo, si los legisladores permanecen sólo un período corto en la cámara baja, no debería perderse de vista que normalmente llegan a ella desde otros puestos legislativos o ejecutivos. De este modo, es posible que no tengan experiencia en las tareas de la Cámara pero sí en la elaboración e implementación de políticas, probablemente a un nivel más bajo (provincial o local) del sistema político. A esto puede agregarse que, en el caso de legislaturas bicamerales, muchos de ellos suelen dejar la Cámara baja para ocupar un asiento en el Senado, cuyos miembros sí suelen acumular más experiencia política y legislativa (Llanos y Sánchez, 2006). Si incorporáramos en nuestros análisis los miembros de las Cámaras altas, probablemente los legisladores no resultarían tan improvisados en sus tareas como se cree.

Sin embargo, la falta de expertise del legislador no es el único factor explicativo del déficit técnico de los parlamentos. En principio, ésta puede ser suplida

En Argentina está en el orden del 17\%, en Brasil del 43\%, en Uruguay más del 50\% y en Chile, del 60\%, Jones et al. (2002); IADB (2005), p. 51. 
o compensada a través del personal técnico de las comisiones y/o las oficinas de asesoramiento del legislador.

\section{APOYO TÉCNICO-PROFESIONAL Y COMISIONES}

Si un parlamento con expertos ofrece una dinámica más constructiva, es una pregunta a la que recientemente se ha comenzado a prestar más atención. Existen muy pocos estudios dedicados al análisis de la capacidad técnica-profesional de los parlamentos ${ }^{24}$. En general, se afirma que la capacidad técnica de los Congresos depende de la estructura de las comisiones legislativas, donde por regla se desarro1la el trabajo legislativo y muchas veces también el monitoreo de las actividades del gobierno, de las estructuras de apoyo de esas comisiones, de las estructuras de apoyo de las bancadas o partidos, y del apoyo técnico de los parlamentarios, tanto individual como institucional (es decir, de los órganos técnicos del Congreso). Debido a la falta de informaciones empíricas y comparativas suficientes sobre los otros aspectos, nos referiremos principalmente a las comisiones legislativas.

Existe un cierto consenso en la literatura científica sobre el hecho de que determinados requisitos son necesarios para que las comisiones legislativas actúen de manera eficiente y, de esta manera, aumenten la capacidad profesional-técnica de los parlamentos en el proceso legislativo y en la supervisión ex-post de la administración. Tales requisitos incluyen, principalmente, que las comisiones no sean demasiado numerosas (porque en ese caso los parlamentarios tienen que dividir su trabajo entre varias comisiones, lo que hace más difícil una especialización legislativa), que el tamaño de cada una no sea demasiado grande (a fin de facilitar el trabajo y la participación del legislador individual), que sus áreas de competencia correspondan a la jurisdicción de los ministerios y, finalmente, que cuenten con apoyo de asesores técnicos ${ }^{25}$.

En América Latina, el número de comisiones permanentes en las Cámaras de diputados varía entre un mínimo de 7 en Colombia y un máximo de 45 en Argentina, lo que, en este último caso, indica un Congreso sobrecargado y poco funcional. El número de comisiones por legislador varía entre 1 y 2 en la mayoría de los casos (5 en Argentina) y, en principio, no es un obstáculo para la especia-

24 Sobre el grado de profesionalización de los parlamentos en 20 países de la OECD ver Z'graggen y Linder (2004). Los indicadores son los ingresos básicos anuales de los diputados, las horas de trabajo de los diputados en el plenario y en las comisiones y los gastos del parlamento por diputado (sin los ingresos de los diputados). Los valores son tratados en relación a los valores de la Cámara de Representantes en EE.UU. Es cuestionable si esta metodología es aplicable en América Latina. Si bien contamos con algunas informaciones sobre los gastos por parlamentario en Alcántara et al. (2005b), p. 248, los riesgos de un mal manejo de fondos están siempre presentes por lo que no parece demasiado confiable usar estos datos como indicadores de profesionalización parlamentaria.

25 Sobre las comisiones parlamentarias en América Latina, ver Casar (1998); Anastasia, Melo y Santos (2004); Alcantara et al. (2005b), pp. 255-282; Saiegh (2005); Santiso (2005). Sobre las comisiones en sistemas parlamentarios ver Mattson/Strom (1995). También Bergman et al. (2003), pp. 169-173. 


\begin{tabular}{|c|c|c|c|c|c|c|c|c|c|c|}
\hline 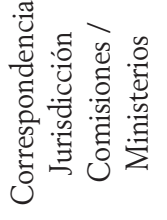 & $\frac{. \pi}{\overrightarrow{0}}$ & 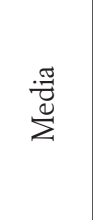 & . & $\frac{\pi}{4}$ & $\stackrel{ت}{ت}$ & . & 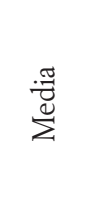 & $\frac{\stackrel{\pi}{\vec{\theta}}}{\stackrel{0}{\Sigma}}$ & $\stackrel{ت}{Z}$ & $\stackrel{\pi}{\frac{\pi}{2}}$ \\
\hline 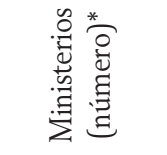 & $\underbrace{\tilde{\Xi}}_{=}$ & $\underset{n}{\stackrel{F}{E}}$ & 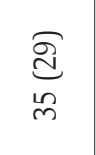 & $\underbrace{\varrho}_{\infty}$ & $\underbrace{\underset{m}{\Xi}}_{m}$ & 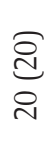 & $\underset{\infty}{\stackrel{6}{e}}$ & $\underbrace{\stackrel{n}{\Xi}}_{\beth}$ & $\begin{array}{l}\Xi \\
\Xi\end{array}$ & $\underbrace{\underset{\sigma}{\Xi}}_{0}$ \\
\hline 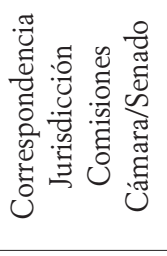 & $\stackrel{ت}{\gtrless}$ & $\stackrel{\Xi}{Z}$ & $\cdot \frac{\pi}{\pi}$ & $\stackrel{ت}{2}$ & $\stackrel{ت}{Z}$ & $i$ & 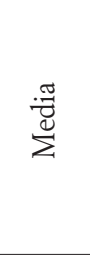 & 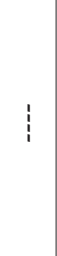 & $\stackrel{ت}{Z}$ & $i$ \\
\hline 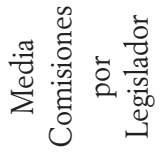 & 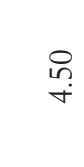 & $\stackrel{0}{6}$ & ठิ & $\stackrel{\leftrightarrow}{\leftrightarrow}$ & $\begin{array}{l}0 \\
\infty \\
0\end{array}$ & $\stackrel{\mathscr{c}}{\sim}$ & $\stackrel{n}{m}$ & 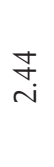 & $\begin{array}{l}\infty \\
\stackrel{0}{0}\end{array}$ & $\hat{\sigma}$ \\
\hline 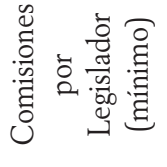 & $\ln \frac{m}{1}$ & $\begin{array}{lr}N \sim \\
1 & 1 \\
-1 & -1\end{array}$ & $\stackrel{v}{1}-$ & $\sim \sim$ & $\stackrel{7}{\infty}$ & $\stackrel{-}{\infty}$ & $\neg \sim$ & $\stackrel{-}{\infty}$ & $\begin{array}{l}m \\
1 \\
\sim\end{array}-$ & - \\
\hline 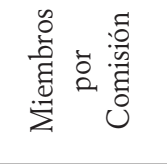 & $\begin{array}{ll}\vec{N} & \stackrel{n}{+} \\
1 & 1 \\
r & \stackrel{n}{n}\end{array}$ & $\begin{array}{cc}n & n \\
1 & 1 \\
m & m\end{array}$ & 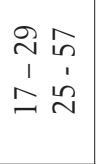 & $\ln 9$ & $\begin{array}{ll}n & n \\
m & m \\
1 & 1 \\
\infty & \infty\end{array}$ & $\stackrel{-}{\text { in }}$ & 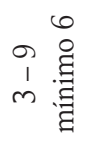 & $\stackrel{-}{\infty}$ & $\begin{array}{ll}a & n \\
1 & 1 \\
n & m\end{array}$ & $\begin{array}{l}\stackrel{2}{N} \\
\stackrel{1}{=}\end{array}$ \\
\hline 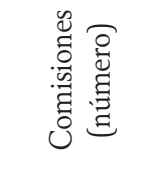 & 守年 & $\bigcirc \simeq$ & $\infty \stackrel{\Omega}{=}$ & $\Omega$ & $n N$ & $\infty$ & 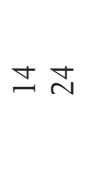 & $\stackrel{\infty}{\sim}$ & $\because \underset{1}{0}$ & $\stackrel{n}{n}$ \\
\hline 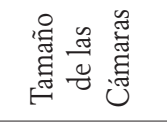 & $\stackrel{N}{N}$ & $\lesssim \vec{n}$ & $\infty \stackrel{m}{n}$ & 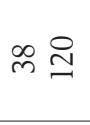 & $\stackrel{\sigma}{6}$ & $\stackrel{\cong}{\beth}$ & In $\infty$ & $\stackrel{\beth}{\beth}$ & m & $\underline{6}$ \\
\hline 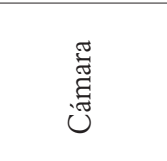 & 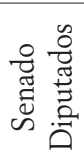 & 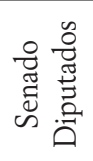 & 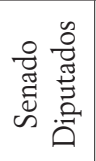 & 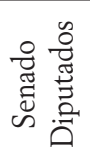 & 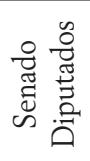 & 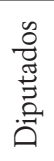 & 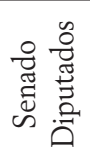 & 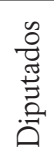 & 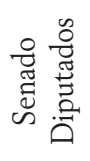 & 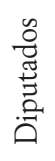 \\
\hline a & 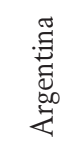 & 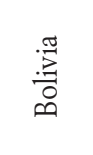 & 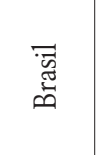 & 节 & $\begin{array}{l}\frac{\pi}{0} \\
\frac{0}{0} \\
0 \\
0\end{array}$ & 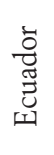 & 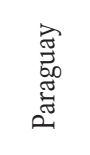 & : & 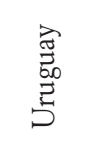 & 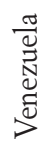 \\
\hline
\end{tabular}


lización de los parlamentarios y para la profesionalización de los parlamentos. Además, en la gran mayoría de los parlamentos bicamerales existe una correspondencia en la jurisdicción de las comisiones en las dos Cámaras, lo que facilita el trabajo legislativo y aumenta la capacidad profesional común. Además, en un 80 por ciento de los parlamentos sudamericanos la correspondencia entre la jurisdicción de las comisiones y ministerios es media o alta. Solamente en una quinta parte de los casos es baja.

Como hemos visto, la influencia de los parlamentos en el proceso legislativo es, en general, limitada y reactiva. Lo mismo se puede constatar respecto a la influencia en el proceso presupuestario ${ }^{26}$. Por esto, los mecanismos de control y monitoreo de la ejecución presupuestaria y las comisiones parlamentarias que participan en la elaboración y el monitoreo del presupuesto cobran importancia. En América Latina -y no sólo en esta región-, el apoyo técnico-profesional con que cuentan estas comisiones es insuficiente. Hoy por hoy, son pocos los parlamentos latinoamericanos (México, Chile, Venezuela y Brasil) que cuentan con un staff calificado y entidades de apoyo especializadas, como las oficinas de presupuesto, para el ejercicio de esta función de control (Santiso, 2005: 28-30).

Finalmente, para llegar a un cuadro completo de las capacidades de control de los parlamentos debería también incluirse la fiscalización que efectúa el parlamento en cooperación o con el apoyo de otros órganos del Estado (como las instituciones de auditoría). Este tema se encuentra, hasta ahora, muy poco investigado.

\section{Conclusiones}

Nos gustaría concluir este trabajo enfatizando que, en la actualidad, se puede constatar una cierta revalorización del papel y de la importancia de los parlamentos en los estudios sobre la consolidación democrática (Fish, 2006). Al principio, muchas investigaciones partieron del supuesto de que en América Latina los Presidentes eran omnipotentes y los parlamentos débiles. Sin embargo, los estudios empíricos acumulados en los últimos diez años nos permiten tener hoy una visión más matizada, según la cual los parlamentos latinoamericanos actúan de manera reactiva, y no pasiva, en el proceso legislativo. Se puede afirmar, asimismo, que esta posición reactiva del parlamento es un punto en común de los sistemas presidenciales y parlamentarios y que, tanto por la distribución de recursos entre el gobierno y el parlamento como por las expectativas de la ciudadanía centradas en que la conducción la ejerce el gobierno, es difícil imaginarse otra constelación. De este modo, un parlamento proactivo sería la excepción y hasta podría ser visto como un síntoma de crisis.

Adicionalmente, el cambio de enfoque desde el hiperpresidencialismo a las presidencias fracasadas (Valenzuela, 2004) nos ha permitido conocer que las re-

26 Ver los poderes presupuestales de los Presidentes en Payne et al. (2003), p.216; PNUD (2004), p. 76, Alcántara et al. (2005b), p. 243. 
laciones de poder entre el Presidente y el Congreso no son estáticas sino dinámicas. En efecto, en los últimos años la posición de muchos Congresos se ha visto reforzada ya que Presidentes con una base de apoyo parlamentario minoritaria han debido ceder espacio político al Congreso, como en el caso de México (Nacif, 2006). En el desenlace de las presidencias fracasadas, es decir, de aquéllas en que los Presidentes tuvieron que renunciar a su cargo antes del fin de su mandato, varios autores percibieron signos de una cierta "parlamentarización" de los sistemas presidenciales (Carey, 2002; Mustapic, 2005; Marsteintredet y Berntzen, 2006). El politólogo argentino Bosoer (2003) habla de un "neo-parlamentarismo de crisis" o de un "neo-parlamentarismo de transición" porque los Congresos dominan el proceso de sucesión. En estos casos, la "legitimidad dual", criticada tanto por Linz como por sus seguidores, impide un vacío de poder porque al lado del Presidente existe otro órgano con una legitimidad directa emanada de la ciudadanía, que está en condiciones de ofrecer una salida a la crisis política. Además, se ha demostrado que, por la pérdida de influencia de las fuerzas armadas, en situaciones de tensiones o conflictos institucionales severos entre el poder ejecutivo y el poder legislativo, normalmente prevalece el parlamento (Pérez-Liñán, 2003; 2005).

No obstante, no hace falta referirse solamente a estas situaciones extremas para revalorizar la influencia de los parlamentos en el proceso político. En este texto intentamos mostrar que en la literatura científica existe un cierto sesgo al analizarse solamente el papel de los parlamentos en el proceso legislativo. Por ello, abogamos por una ampliación de la perspectiva, que incluya también la dimensión de control político, la cual, se puede sostener, es aún más importante en legislaturas reactivas. Como hemos visto, esta perspectiva incluye tanto el papel del parlamento en el proceso legislativo, controlando al gobierno y corrigiendo sus iniciativas legislativas, como el monitoreo de la ejecución de las leyes y de otras actividades del gobierno. Tal vez sería útil tomar en cuenta debidamente este aspecto del diseño institucional en las frecuentes discusiones sobre una mayor parlamentarización de los sistemas presidenciales en América Latina. Estas discusiones se han concentrado hasta ahora solamente en la (re)distribución de poderes entre el Presidente y el Congreso en el proceso legislativo, desestimando otras instituciones, como las que regulan el uso de los mecanismos de control del poder ejecutivo.

Finalmente, no son solamente las atribuciones formales en el proceso legislativo y de control político las que definen el poder del parlamento. Hemos visto en estas páginas que los parlamentos reactivos según sus atribuciones en el proceso legislativo pueden cumplir ese papel con diferentes grados de eficiencia. Por esto, un análisis exhaustivo de los parlamentos debe analizar también el impacto de la organización interna de los parlamentos y sus capacidades técnicas en el desempeño de tales funciones. Estos aspectos han sido, hasta ahora, subestimados en las discusiones y estudios de ciencia política sobre los Congresos latinoamericanos. Tal vez es más fácil reformar esas instituciones técnicas, que son de competencia exclusiva del parlamento, que la distribución de poderes y atribuciones entre el parlamento y el Presidente. Para concluir, nos gustaría recordar, una vez más, 
que los parlamentos reactivos en tiempos normales pueden jugar un papel muy activo en tiempos de crisis.

\section{Bibliografía}

Agor, Weston (ed.). 1971. Latin American Legislatures: Their Role and Influence. Analyses for Nine Countries. New York: Praeger.

Alcántara, Manuel (ed.). 2006. Políticos y política en América Latina. Madrid: Fundación Carolina y Editorial Siglo XXI.

Alcántara, Manuel; García, Mercedes; Sánchez, Francisco. 2005a. El poder legislativo en América Latina a través de sus normas. Salamanca: Ediciones Universidad de Salamanca.

Alcántara, Manuel; García, Mercedes; Sánchez, Francisco. 2005b. Funciones, procedimientos y escenarios: un análisis del poder legislativo en América Latina. Salamanca: Ediciones Universidad de Salamanca.

Alonso, Guillermo V. julio-septiembre 1998. "Democracia y reformas: las tensiones entre decretismo y deliberación. El caso de la reforma previsional argentina”. Desarrollo Económico. Revista de Ciencias Sociales 38 (150): 595-626.

Ames, BARry. 1998. Toward a Theory of Legislative Parties in Brazil, Artículo preparado para el Latin American Congress Project Conference, CIDE, Ciudad de México, Febrero $5-8,1998$.

Amorin NetoOctavio; Cox, Gary W.; McCubbins, Mathew D. 2003. "Agenda Power in Brazil's Câmara dos Deputados, 1989-98”. World Politics 55 (4): 550-578.

Amorim Neto, Octavio; Tafner, Paulo. 2002. "Governos de Coalizão e Mecanismos de Alarme de Incêndio no Controle Legislativo das Medidas Provisórias". Dados. Revista de Ciências Sociais 45 (1): 5-38.

Anastásia, Fátima; Melo, Carlos Ranulfo; Santos, Fabiano. 2004. Governabilidade e representação política na América do Sul. Río de Janeiro: Fundação Editora da UNESP.

Bergman, Torbjörn et al. 2003. "Democratic Delegation and Accountability". En Kaare Strom, Wolfgang C. Muller \& Torbjörn Bergman (eds.), Delegation and Accountability in Parliamentary Democracies, Oxford/New York: Oxford University Press, 109-220.

Blondel, JeAn. 1973. Comparative Legislatures. Englewood Cliffs: Prentice-Hall.

Bosoer, FabiÁn. 2003. "1999-2003: el auto-rescate de las democracias sudamericanas. Una hipótesis sobre la eficacia del 'componente' parlamentario". Debates Latinoamericanos 1.1 (octubre). Buenos Aires. http://www.rlcu.org. ar/revista/articulos. asp?numero=0101-Octubre-2003

Calcagnotto, Gilberto. 2005. "Comissões Parlamentares de Inquérito no Brasil e na Alemanha: Semelhanças e Diferenças”. En Mariana Llanos \& Ana-Maria Mustapic (eds.), Controle parlamentar na Alemanha, na Argentina e no Brasil. Río de Janeiro: Konrad Adenauer Stiftung, 171-193.

Carey, John M. 2002. "Legislatures and Political Accountability. Building Credibility". Harvard Review of Latin America, 2 (1): 32-34.

Carey, John M.; Shugart, Matthew Soberg (eds.). 1997. Executive Decree Authority. Cambridge: Cambridge University Press.

CASAR, MARÍA Amparo. 1998. Los sistemas de comisiones en los reglamentos parlamentarios de América Latina. Un estudio comparado. México: CIDE. Documento de Trabajo EP-83.

Castro Santos, Maria Helena. 1997. "Governabilidade, Governança e Democracia: Criação de Capacidade Governativa e Relações Executivo-Legislativo no Brasil Pós-Constituinte". Dados. Revista de Ciências Sociais 40 (3): 335-376. 
Chasquetti, Daniel. 2001. "Democracia, Multipartidismo y Coaliciones: evaluando la difícil combinación". En J. Lanzaro (comp.) Tipos de presidencialismo y coaliciones politicas en América Latina. Buenos Aires: CLACSO, 319-359

Cheibub, José Antonio. 2002. "Minority Governments, Deadlock Situations, and the Survival of Presidential Democracies". Comparative Political Studies 35 (3): 284-312.

Close, David (ed.). 1995. Legislatures and the New Democracies in Latin America, Boulder/ London: Lynne Rienner Publishers.

Colomer, Josep M. (ed.). 1996. Political Institutions in Europe, London/New York: Routledge.

Colomer, Josep M.; Negretto, Gabriel L. 2005. "Can Presidentialism Work Like Parliamentarism?" Government and Opposition 40 (1): 60-89.

Colomer, Josep M.; Negretto, Gabriel L. 2003. "Gobernanza con poderes divididos en América Latina”. Política y Gobierno 10 (1): 13-61.

Cox, Gary W.; Morgenstern, Scott. 2002. "Epilogue: Latin America's Reactive Assemblies and Proactive Presidents". En Morgenstern, Scott \& Nacif, Benito (eds.), Legislative Politics in Latin America. Cambridge: Cambridge University Press, 446-468.

Diamond, Larry. 1996. "Democracy in Latin America. Degrees, Illusions, and Directions for Consolidation”. En T. Farer (ed.), Beyond Sovereignty. Collectively Defending Democracy in the Americas. Baltimore \& London: The John Hopkins University Press.

Eaton, Kent. 2002. "Fiscal Policy Making in the Argentine Legislature". En Scott Morgensten \& Benito Nacif, Legislative Politics in Latin America. Cambridge: Cambridge University Press, 287-314.

Etchemendi, Sebastián; Palermo, Vicente. Enero-marzo 1998. "Conflicto y concertación. Gobierno, Congresos y organizaciones de interés en la reforma laboral del primer gobierno de Menem (1989-1995)". Desarrollo Económico. Revista de Ciencias Sociales 37 (148): 559-590.

Figueiredo, Argelina Cheibub; Limongi, Fernando. 1999. Executivo e Legislativo na nova ordem constitucional. Río de Janeiro: Editora FGV.

Figueiredo, Argelina Cheibub; Limongi, Fernando. 2000. "Presidential Power, Legislative Organization, and Party Behavior in Brazil". Comparative Politics 32 (2): 151-170.

Fuchs, Ruth; Nolte, Detlef. 2005. "Los pedidos de información escritos y orales como instrumentos de control parlamentario: Argentina y Alemania desde una perspectiva comparada". En M. Llanos y A. Mustapic, Controle parlamentar na Alemanha, na Argentina e no Brasil. Río de Janeiro: Konrad Adenauer Stiftung, 61-83.

Helmke, Gretchen; Levitsky, Steven. 2004. "Informal Institutions and Comparative Politics: a Research Agenda". Perspectives on Politics 2 (4): 725-740.

Huneeus, Carlos; Berrios, Fabiola. 2004. El Congreso Nacional en un régimen presidencial. El caso de Chile. Santiago de Chile: CERC.

Huneeus, Carlos. 2005. “Por qué ha funcionado el presidencialismo en Chile? Factores institucionales y el liderazgo de Patricio Aylwin”. Persona y Sociedad 19 (2): 11-54.

IADB (Inter-American Development Bank). 2005. The Politics of Policies. Economic and Social Progress in Latin America. Washington D.C.: IADB.

KAISER, ANDRÉ. 1998a. "Vetopunkte der Demokratie. Eine Kritik neuerer Ansätze der Demokratietypologie und ein Alternativvorschlag”. Zeitschrift für Parlamentsfragen 29 (3): 525-541.

KAISER, ANDRé. 1998b. "Institutional regimes". En Jan W. van Deth (ed.), Comparative Politics. The problem of equivalence. London/ New York: Routledge, 205-221.

Krumwiede, Heinrich; Nolte, Detlef. 2000. Die Rolle der Parlamente in den Präsidialdemokratien Lateinamerikas (Beiträge zur Lateinamerika-Forschung 4). Hamburgo, Institut für Iberoamerika-Kunde. 
Jones, Mark. 2001. "Political Institutions and Public Policy in Argentina: An Overview of the Formation and Execution of the National Budget". En S. Haggard y M. McCubbins (eds.), Presidents, Parliaments, and Policy. Cambridge: Cambridge University Press, 149-182.

Jones Mark; Tommassi Mariano; Saiegh Sebastián; Spiller Pablo. 2002. "Amateur Legislators-Professional Politicians: The Consequences of Party-Centred Electoral Rules in a Federal System”. American Journal of Political Science 46 (3): 656-669.

Lemos, Leany. 2005. "Como o Congresso brasileiro controla o Executivo? O uso de Requerimentos de Informação, Convocação de Autoridades e Propostas de Fiscalização e Controle". En M. Llanos y A. Mustapic, Controle parlamentar na Alemanha, na Argentina e no Brasil. Río de Janeiro: Konrad Adenauer Stiftung, 85-112.

Lemos, Leany Barreiro de S. 2001. "The Brazilian Congress and the distribution of social benefits during the period 1988-1994: a distributist analysis". Dados 44 (3): 561-630.

Limongi, Fernando; Figueiredo, Argelina. 1998. "Bases institucionais do presidencialismo de coalizão". Lua Nova. Revista de Cultura e Politica 44: 81-106.

Limongi, Fernando; Figueiredo, Argelina. 2004. "Modelos de Legislativo: O Legislativo Brasileiro em Perspectiva". Plenarium 1 (1): 41-56.

Llanos, Mariana. 2002. Privatization and Democracy in Argentina. An Analysis of PresidentCongress Relations. Palgrave/St Antony's College Series, Houndmills: Palgrave.

Llanos, Mariana. octubre-diciembre 1998. "El Presidente, el Congreso y la política de privatizaciones en la Argentina (1989-1997)”. Desarrollo Económico. Revista de Ciencias Sociales 38 (151): 743-770.

Llanos, Mariana; Lemos, Leany Barreiro. 2006. The Politics of Senatorial Confirmations: a Comparative Study of Argentina and Brazil in Comparative Perspective, Working Paper Global and Area Studies Nr. 18, Hamburg: GIGA.

Llanos, Mariana; Nolte, Detlef. 2003. "Bicameralism in the Americas: Around the Extremes of Symmetry and Incongruence". Journal of Legislative Studies 9 (3): 54-86.

Llanos, Mariana; Sánchez López, Francisco. 2006. "Councils of Elders? The Senates and its members in the Southern Cone". Latin American Research Review 41 (1): 133-152.

March, James; Olsen, Johan. 1989. Rediscovering Institutions. The Organizational Basis of Politics. New York: Free Press.

Marsteinredet, Leiv; Berntzen, Einar. Abril 25-30 de 2006. Latin American Presidentialism: Reducing the perils of presidentialism through presidential interruptions, Paper preparado para el ECPR Joint Sessions of Workshops, Nicosia.

Mattson, Ingvar; Strom, KaAre. 2003. "Parliamentary Committees". En Herbert Döring (ed.), Parliaments and Majority Rule in Western Europe. Frankfurt/New York: Campus, 223-246.

Moreno E., Crisp B.; Shugart, M. 2003. "The Accountability Deficit in Latin America”. En S. Mainwaring \& C. Welna (comps.), Democratic Accountability in Latin America. New York: Oxford University Press, 79-131.

Morgenstern, Scott. 2002. "Explaining Legislative Politics in Latin America". En Morgenstern, Scott \& Nacif, Benito (eds.), Legislative Politics in Latin America. Cambridge: Cambridge University Press, 413-445.

Mustapic, Ana María. 2005. "Inestabilidad sin colapso. La renuncia de los Presidentes: Argentina en el año 2001”. Desarrollo Económico 45 (178): 263-280.

Mustapic, AnA María. enero-marzo 2000. "Oficialistas y diputados: las relaciones Ejecutivo-Legislativo en la Argentina". Desarrollo Económico. Revista de Ciencias Sociales 39 (156): 571-595.

Nacif, Benito. 2006. The Fall of the Dominant Presidency: Lawmaking Under Divided in Mexico. México: CIDE. División de Estudios Políticos, Documento de Trabajo Nº 185. 
Nacif, Benito. 2002. "Understanding Parety Discipline in the Mexican Chamber of Deputies: the Centralized Party Model”. En Morgenstern, Scott \& Nacif, Benito (eds.), Legislative Politics in Latin America. Cambridge: Cambridge University Press, 254-286.

Negretto, Gabriel L. 2006a. "Minority Presidents and Types of Government in Latin America". Latin American Politics and Society 48 (3): 63-92.

Negretto, Gabriel L. Abril 25-30 2006b. Multiparty Systems and Institutional Design. Explaining Constitutional Change in Latin America, Paper preparado para el ECPR Joint Sessions of Workshops, Nicosia.

Negretto, Gabriel L. 2004. "Government Capacities and Policy Making By Decree in Latin America. The Cases of Brazil and Argentina". Comparative Political Studies 37 (5): 531-562.

Negretto, Gabriel. 2003. "Diseño constitucional y separación de poderes en América Latina". Revista Mexicana de Sociología 65 (1): 41-76.

Neiva, Pedro Robson Pereira. 2004. Estudo Comparado de Câmaras Altas: Os Poderes e o Papel dos Senados nos Sistemas Presidencialistas, Tesis de doctorado en Ciencia Política, Río de Janeiro: IUPERJ.

Nino, Carlos. 1992. Fundamentos de Derecho constitucional. Análisis filosófico, jurídico y politológico de la práctica constitucional. Buenos Aires: Editorial Astrea.

Nolte, Detlef. 2006a. "El presidencialismo chileno después de 1989. Lecturas divergentes”. En Manuel Alcántara \& Leticia M. Ruiz Rodríguez (eds.), Chile. Política y modernización democrática. Barcelona: Ediciones Bellaterra, 129-164.

Nolte, Detlef. 2006b. "¿Son dos cámaras mejor que una? Los sistemas bicamerales de América Latina”. En Klaus Bodemer \& Fernando Carillo (eds.), Gobernabilidad y Reforma Politica en América Latina. La Paz: Edición Plural. Por publicarse.

Nolte, Detlef. 2005. "Neoinstitutionalismus und Demokratieforschung in Lateinamerika: präsidentielle Regierungssysteme als komplexe institutionelle Regimes". En Ulf Engel, Cord Jakobeit, Andreas Mehler \& Gunter Schubert (Hrsg.), Staat, Demokratie und Entwicklung im Zeitalter der Globalisierung. Festschrift für Rainer Tetzlaff, Münster: LIT, 336-349.

Nolte, Detlef. 2004a (diciembre). "Pautas de orientación socioeconómica y perfil ideológico de los senadores en el Cono Sur". América Latina Hoy 38: 101-123.

Nolte, Detlef. 2004b. "Presidentialism revisited: Gewaltentrennung und Gewaltenverschränkung in den lateinamerikanischen Präsidialdemokratien". Lateinamerika Analysen 7: 55-88.

Nolte, Detlef. 2003. "Funciones y funcionamiento de los Senados en los sistemas bicamerales de América Latina: un enfoque comparado”. Res Pública 3: 9-61.

Nolte, Detlef; Sánchez, Francisco. 2004. "El Senado chileno: pautas de representación política y perfil ideológico". En Carolina Stefoni (eds.), Chile 2003-2004. Los nuevos escenarios (inter) nacionales. Santiago de Chile: FLACSO, 323-344.

O’Donnell, Guillermo. 2003. "Horizontal Accountability: The Legal Institutionalization of Mistrust". En S. Mainwaring y C. Welna, Democratic Accountability in Latin America. New York: Oxford University Press, 43-54.

O’Donnell, Guillermo. 1998. "Horizontal Accountability in New Democracies". Journal of Democracy 9 (3): 112-126.

O’Donnell, Guillermo. 1994. "Delegative Democracy”. Journal of Democracy 5 (1): 55-69.

PAlAnZA, VAleria. 2005. "Delegação e controle parlamentar na Argentina”. En M. Llanos y A. Mustapic, Controle parlamentar na Alemanha, na Argentina e no Brasil. Río de Janeiro: Konrad Adenauer Stiftung, 25-60.

Palermo, Vicente. 2000. "Como se Governa o Brasil? O Debate sobre Instituções Políticas e Gestão de Governo”. Dados 43 (3): 521-557. 
Payne, J. Mark et al. 2002. Democracies in Development. Politics and Reform in Latin America. Washington D.C.: IDEA-Inter-American Development Bank.

Pérez-Liñan, Aníbal S. 2005. "Democratization and Constitutional Crisis in Presidential Regimes. Toward Congressional Supremacy?". Comparative Political Studies 38 (1): $51-74$.

Pérez-Liñan, Aníbal S. 2003. "Pugna de poderes y crisis de gobernabilidad. ¿Hacia un nuevo presidencialismo?". Latin American Research Review 38 (2): 149-164.

Peters, B. Guy. 1999. Institutional Theory in Political Science. London/New York: Continuum International.

Philip, George. 1993. "The New Economic Liberalism and Democracy in Latin America: Friends or Enemies?". Third World Quarterly 14 (3): 555-571.

Philip, George. 1998. "The New Populism, Presidentialism, and Market-Orientated Reform in Spanish South America". Government and Opposition 33 (1): 81-97.

Philip, George. 1999. "The Dilemmas of Good Governance: A Latin American Perspective". Government and Opposition 34 (2): 226-242.

Przeworski, Adam. 1995. Sustainable Democracy. Cambridge: Cambridge University Press.

Przeworski, Adam. 1991. Democracy and the Market: Political and Economic Reforms in Eastern Europe and Latin America. New York: Cambridge University Press.

ReIch, Gary. 2002. "Executive Decree Authority in Brazil: How Reactive Legislators Influence Policy". Legislative Studies Quarterly 27 (1): 5-31.

Saiegh, Sebastian M. Feb. 28-marzo 2005. The Role of Legislatures in the Policymaking Process, Paper preparado para el "Workshop on State Reform, Public Policies and Policymaking”, Inter-American Development Bank, Washington D.C.

Santiso, Carlos. 12-13 diciembre 2005. Parliaments and Budgeting, Paper preparado para el "Third Annual Meeting RedGob", Hamburgo.

Sartori, Giovanni. 1992. Elementos de Ciencia Politica. Madrid: Alianza Editorial.

SCHIAVON, Jorge A. 2004. "Bicameralismo, configuración institucional y partidaria en América Latina: un modelo de puntos y jugadores con veto para explicar la provisión de políticas públicas". Foro Internacional 54 (1), N 175: 126-149.

Shugart, Matthew Soberg; Haggard, Stephan. 2001. "Institutions and Public Policies in Presidential Systems”. En Haggard, Stephan H. \& McCubbins, Mathew D. (eds.), Presidents, Parliaments, and Policy. Cambridge: Cambridge University Press, 64-104.

Siavelis, Peter M. 2000. The President and Congress in Postauthoritarian Chile. Institutional Constraints to Democratic Consolidation. University Park, Pennsylvania: Penn State Press.

StefFani, Winfried. 1989. "Formen, Verfahren und Wirkungen parlamentarischer Kontrolle". En Hans-Peter Schneider y Wolfgang Zeh (eds.), Parlamentsrecht und Parlamentspraxis. Berlin/New York: de Gruyter, 1325-1367.

Tsebelis, G.; Money, J. 1997. Bicameralism. Cambridge: Cambridge University Press.

Z'Graggen, Heidi; Linder, Wolf. 2004. Professionalisierung der Parlamente im internationalen Vergleich. Universität Bern, Institut für Politikwissenschaft. 